\title{
Respiratory Rehabilitation in the COVID-19 Era
}

\author{
Venerino Poletti ${ }^{a, b} \quad$ Alberto Capozzolo ${ }^{c, d}$

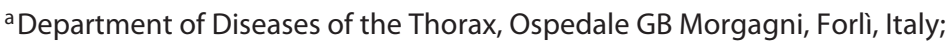 \\ ${ }^{\mathrm{b}}$ Department of Respiratory Diseases and Allergy, Aarhus University Hospital, Aarhus, Denmark; \\ 'ICS Maugeri, Pavia, Italy; ${ }^{d}$ Institute of Respiratory Diseases, University of Bari, Bari, Italy
}

Respiratory rehabilitation began to be known and applied in Italy in the 1970s, following the example of the Brompton Hospital in London, with the introduction of "chest physiotherapy" in the treatment of cystic fibrosis patients. After the introduction of oxygen therapy, it has proven effective in the treatment of chronic inflammatory lung diseases such as chronic obstructive pulmonary disease [1] (with degree of evidence A) and has extended its range over time, showing evidence also in bronchial severe asthma [2] and idiopathic pulmonary fibrosis [3]. However, the nature of respiratory rehabilitation intervention, defined as "a multidisciplinary intervention based on personalized evaluation and treatment which includes, but is not limited to, exercise training, education, behavior modification, and designed to improve physical and psychological condition of people with respiratory disease," has not yet completed its path, showing over time the possibility of extending the range of action to the treatment of sequelae in severe acute pulmonary infectious diseases such as tuberculosis [4] and ARDS secondary to influenza virus [5].

In this issue, these big premises prompted Vitacca et al. [12] to define the role of respiratory rehabilitation in the treatment of patients suffering from severe respiratory insufficiency and from postinflammatory sequelae affecting the lung parenchyma, both due to Covid-19 infection.

\footnotetext{
karger@karger.com

(c) 2020 S. Karger AG, Basel

www.karger.com/res

Karger
}

However, it is necessary to focus on a topic sometimes overlooked. The rehabilitative intervention, historically aimed to patients with previous respiratory disease and often confined in dedicated operative units, has indications already in the acute setting, while serious organ deficits remain an absolute contraindication. In the last 10 years, in fact, the scientific production related to early and progressive mobilization of intensive care unit (ICU) patients has increased $[6,7]$. It has now been shown that early mobilization intervention in patients admitted to intensive care for an episode of acute respiratory failure requiring mechanical ventilation for more than 4 days is safe and feasible [8]. This is also evident in terms of bed reduction and Iength of ICU stay, without an increase in costs [9], and a better percentage of return to pre-existing conditions [10]. The key aspect of this evidence indicates that muscle weakness and physical deconditioning, which may follow the ICU stay, are responsible for important sequences on their own and could compromise the functional status of the patient for many years after the acute event. This relatively new aspect brings attention to the versatility of the rehabilitative intervention in the acute as well as chronic patient, and finds the path to success in personalized intervention. Therefore, in a schematic analysis of the intervention, we can say that in both cases, each specific area of impairment for each patient must be focused on [11], such as: aerobic exercise for patients with

\footnotetext{
Venerino Poletti

Dipartimento di Malattie dell' Apparato Respiratorio Ospedale GB Morgagni

Via Carlo Forlanini, 34, Pavilion Morgagni, IT-47100 Forlì (Italy)

venerino.poletti@gmail.com
} 
respiratory/motor problems and physical deconditioning; strength training for peripheral muscle weakness; training in techniques favoring bronchial secretion removal in hypersecretive post-acute patients; evaluation of basic activities of daily life; evaluation of patients' ability to improve recovery or adaptation to basic activities of daily life with the support of physiotherapists and occupational therapists; and last but not least, neuropsychological training consisting in counselling sessions, psychological support, and cognitive training. The program, in the acute setting of a COVID center, must go simultaneously with the containment of droplet formation in order to avoid the risk of contagion.

The position paper by Vitacca et al. [12], which focuses on a very broad topic, could only be divided into areas of direction and structured schematically, highlighting, point by point, the key factors of the rehabilitative intervention and briefly explaining the methods. The result was a document that, on the one hand, directs the pulmonologist to use correctly the rehabilitation techniques already acquired, adapting to the specific situation, and on the other, leaves the possibility to customize the interven- tion, thus increasing the potential for success towards all patients.

In any respiratory disease that determines organ damage determining potentially remote sequelae, orotracheal intubation with the need for mechanical ventilation and subsequent tracheotomy with consequent prolonged entrapment will always be worthy for rehabilitation. It must be undertaken only when the patient's conditions allow a partial recovery of autonomous motor and respiratory activity, and must continue in parallel with the pneumological treatment, be it pharmacological, ventilatory, or interventional, until the patient can resume autonomously the activities of daily life. The latter result is the only term that can appropriately accompany the word healing, often improperly associated with the term discharge.

In conclusion, we are convinced that the position statement by Vitacca et al. [12] will be able to guide your rehabilitation path for the patient, up to true healing, indicating on the one hand correct choices in respiratory rehabilitation, and on the other showing behaviors necessary to maintain the right safety profile for all healthcare workers involved.

\section{References}

1 Lacasse Y, Brosseau L, Milne S, Martin S, Wong E, Guyatt GH, et al. Pulmonary rehabilitation for chronic obstructive pulmonary disease. Cochrane Database Syst Rev. 2002; 88(3):CD003793.

2 Zampogna E, Centis R, Negri S, Fiore E, Cherubino F, Pignatti P, et al. Effectiveness of pulmonary rehabilitation in severe asthma: a retrospective data analysis. J Asthma. 2019 Aug 13;1-7. Online ahead of print.

3 Kenn K, Gloeckl R, Behr J. Pulmonary rehabilitation in patients with idiopathic pulmonary fibrosis-a review. Respiration. 2013; 86(2):89-99.

4 Ando M, Mori A, Esaki H, Shiraki T, Uemura $\mathrm{H}$, Okazawa $\mathrm{M}$, et al. The effect of pulmonary rehabilitation in patients with post-tuberculosis lung disorder. Chest. 2003 Jun;123(6): 1988-95.
5 Hsieh MJ, Lee WC, Cho HY, Wu MF, Hu HC, $\mathrm{Kao} \mathrm{KC}$, et al. Recovery of pulmonary functions, exercise capacity, and quality of life after pulmonary rehabilitation in survivors of ARDS due to severe influenza A (H1N1) pneumonitis. Influenza Other Respir Viruses. 2018 Sep;12(5):643-8.

6 Stiller K. Physiotherapy in intensive care: an updated systematic review. Chest. 2013 Sep; 144(3):825-47.

7 Kayambu G, Boots R, Paratz J. Physical therapy for the critically ill in the ICU: a systematic review and meta-analysis. Crit Care Med. 2013 Jun;41(6):1543-54.

8 Bailey P, Thomsen GE, Spuhler VJ, Blair R, Jewkes J, Bezdjian L, et al. Early activity is feasible and safe in respiratory failure patients. Crit Care Med. 2007 Jan;35(1):139-45.

9 Morris PE, Goad A, Thompson C, Taylor K, Harry B, Passmore L, et al. Early intensive care unit mobility therapy in the treatment of acute respiratory failure. Crit Care Med. 2008 Aug;36(8):2238-43.
10 Schweickert WD, Pohlman MC, Pohlman AS, Nigos C, Pawlik AJ, Esbrook CL, et al. Early physical and occupational therapy in mechanically ventilated, critically ill patients: a randomised controlled trial. Lancet. 2009 May;373(9678):1874-82.

11 Lau HM, Ng GY, Jones AY, Lee EW, Siu EH, Hui DS. A randomised controlled trial of the effectiveness of an exercise training program in patients recovering from severe acute respiratory syndrome. Aust J Physiother. 2005; 51(4):213-9.

12 Vitacca M, Carone M, Clini E, Paneroni M, Lazzeri M, Lanza A, et al., on behalf of the Italian Thoracic Society (ITS - AIPO), the Association for the Rehabilitation of Respiratory Failure (ARIR) and the Italian Respiratory Society (SIP/IRS). Joint statement on the role of respiratory rehabilitation in the COVID-19 crisis: the Italian position paper. Respiration. 2020. DOI: 10.1159/000508399. 